\title{
Detecting the genetic link between Alzheimer's disease and obesity using bioinformatics analysis of GWAS data
}

\author{
Qi-Shuai Zhuang ${ }^{1, *}$, Hao Zheng ${ }^{1, *}$, Xiao-Dan $\mathrm{Gu}^{1}$, Liang Shen ${ }^{1}$ and Hong-Fang $\mathrm{Ji}^{1}$ \\ ${ }^{1}$ Shandong Provincial Research Center for Bioinformatic Engineering and Technique, School of Life Sciences, Shandong \\ University of Technology, Zibo, P. R. China \\ ${ }^{*}$ These authors have contributed equally to the work \\ Correspondence to: Liang Shen, email: shen@sdut.edu.cn
}

Hong-Fang Ji, email: jhf@sdut.edu.cn

Keywords: Alzheimer's disease, obesity, bioinformatics, genome-wide association studies, single nucleotide polymorphisms, Gerotarget

Received: April 07, $2017 \quad$ Accepted: June 18, $2017 \quad$ Published: July 08, 2017

Copyright: Zhuang et al. This is an open-access article distributed under the terms of the Creative Commons Attribution License 3.0 (CC BY 3.0), which permits unrestricted use, distribution, and reproduction in any medium, provided the original author and source are credited.

\section{ABSTRACT}

Alzheimer's disease (AD) represents the major form of dementia in the elderly. In recent years, accumulating evidence indicate that obesity may act as a risk factor for $A D$, while the genetic link between the two conditions remains unclear. This bioinformatics analysis aimed to detect the genetic link between AD and obesity on single nucleotide polymorphisms (SNPs), gene, and pathway levels based on genomewide association studies data. A total of 31 SNPs were found to be shared by AD and obesity, which were linked to 7 genes. These genes included PSMC3, CELF1, MYBPC3, SPI1, APOE, MTCH2 and RAPSN. Further functional enrichment analysis of these genes revealed the following biological pathways, including proteasome, osteoclast differentiation, hypertrophic cardiomyopathy, dilated cardiomyopathy, Epstein-Barr virus and TLV-I infection, as well as several cancer associated pathways, to be common among AD and obesity. The findings deepened our understanding on the genetic basis linking obesity and AD and may help shape possible prevention and treatment strategies.

\section{INTRODUCTION}

Alzheimer's disease (AD) is a progressive and irreversible neurodegenerative disease discovered by Alois Alzheimer in 1906. AD is the most frequent cause of dementia and is estimated to affect 30 million subjects worldwide, and the prevalence of $\mathrm{AD}$ is expected to rise steadily with the aging of population in the following decades $[1,2]$. Obesity is one of the most prevalent nutritional disorder around the world and the global pandemic of obesity has been a significant public health issue [3]. Obesity have been reported to act as an important risk factor for a variety of diseases, including diabetes, cardiovascular disease, hypertension, cancers, and etc.. [4-8]. In recent years, a growing body of evidence supports that obesity can increase the risk of developing $\mathrm{AD}$ [9-12]. For instance, an 18-year followup study found that overweight at high ages can increase the risk of developing AD in women [10]. Another study revealed that compared to the subjects with a normal body mass index $(\mathrm{BMI})$, those obese $(\mathrm{BMI}>$ or $=30)$ at midlife exhibited a 3.1 fold increase in the incidence of $\mathrm{AD}$, suggesting that midlife obesity can strongly predict the risk of $\mathrm{AD}$ [11].

As there is no effective agents to combat $\mathrm{AD}$ so far, more efforts have been devoted to identifying the modifiable risk factors and elucidating the underlying mechanisms to help prevent this disease. Thus, it is interesting to explore the genetic basis underlying the ADobesity link. In the past decade, genome-wide association studies (GWAS) were successful to identify genetic variants underlying susceptibility to individual disease conditions like $\mathrm{AD}$ and obesity, while limited information exists on shared genetic factors between them. Therefore, in this study, we executed a bioinformatics analysis on the overlapped single nucleotide polymorphisms (SNPs), genes and biological pathways on the basis of meta-GWAS data to explore the genetic link between $\mathrm{AD}$ and obesity. 
Table 1: Overlapped SNPs associated with AD and obesity with multiple cutoff $p$-values criteria

\begin{tabular}{|c|c|c|c|}
\hline \multirow{2}{*}{$p$-value } & \multicolumn{2}{|c|}{ Number of SNPs } & \multirow{2}{*}{ Overlapped SNPs } \\
\hline & AD & Obesity & \\
\hline $1.0 \mathrm{E}-7$ & 1176 & 2195 & 0 \\
\hline $1.0 \mathrm{E}-6$ & 1548 & 3071 & rs405509 \\
\hline $1.0 \mathrm{E}-5$ & 2746 & 4963 & 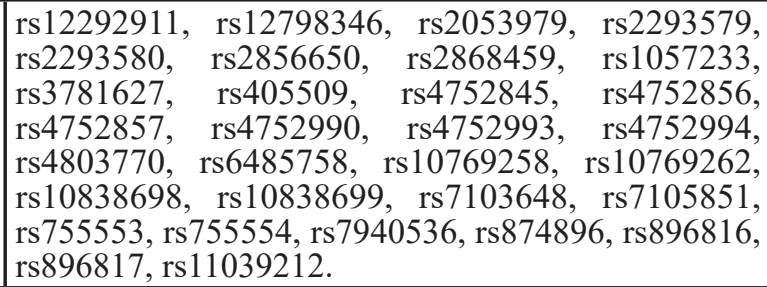 \\
\hline
\end{tabular}

Table 2: Genes and biological pathways likely to be shared between AD and obesity

\begin{tabular}{|l|c|c|c|}
\hline \multicolumn{1}{|c|}{ Biological pathways } & Total pathway size & Enriched genes & Benjamini-corrected $\boldsymbol{p}$-value \\
\hline Proteasome & 4 & PSMC3 & $2.64 \mathrm{E}-06$ \\
\hline Epstein-Barr virus infection & 18 & PSMC3, SPI1 & $3.05 \mathrm{E}-06$ \\
\hline Hypertrophic cardiomyopathy & 1 & MYBPC3 & $2.04 \mathrm{E}-06$ \\
\hline Dilated cardiomyopathy & 1 & MYBPC3 & $2.04 \mathrm{E}-06$ \\
\hline Osteoclast differentiation & 14 & SPI1 & $3.17 \mathrm{E}-06$ \\
\hline HTLV-I infection & 14 & SPI1 & $3.17 \mathrm{E}-06$ \\
\hline Pathways in cancer & 14 & SPI1 & $3.17 \mathrm{E}-06$ \\
\hline Transcriptional misregulation in cancer & 14 & SPI1 & $3.17 \mathrm{E}-06$ \\
\hline Acute myeloid leukemia & 14 & SPI1 & $3.17 \mathrm{E}-06$ \\
\hline Alzheimer's disease & 1 & APOE & $1.33 \mathrm{E}-07$ \\
\hline
\end{tabular}

\section{RESULTS}

Based on independent the International Genomics of Alzheimer's Project (IGAP) or Genetic Investigation of Anthropometric Traits (GIANT) data, we identified SNPs associated with $\mathrm{AD}$ or obesity with multiple p-values as cutoff criteria (Table 1). When setting at p-value of 1.0E05 as cutoff criteria, the number of identified SNPs for the two diseases was comparable (2746 SNPs associated with $\mathrm{AD}$ and 4963 SNPs with obesity). Through overlapping the two sets of data, 31 SNPs were identified to be linked with both diseases, which included rs12292911, rs12798346, rs2053979, rs2293579, rs2293580, rs2856650, rs2868459, rs 1057233 , rs 3781627 , rs405509, rs4752845, rs4752856, rs4752857, rs4752990, rs4752993, rs4752994, rs4803770, rs6485758, rs10769258, rs10769262, rs10838698, rs10838699, rs7103648, rs 7105851, rs755553, rs755554, rs7940536, rs874896, rs896816, rs896817, and rs 11039212 . When setting the threshold at $p$-value $\leq 1.0 \mathrm{E}$ 06 , there was only 1 overlapped SNPs, rs 405509 , between $\mathrm{AD}$ and obesity. When setting the threshold at $\mathrm{p}$-value $\leq$ 1.0E-07, no overlapped SNPs was found.

Among the overlapped $31 \mathrm{SNPs}$, there were 28 SNPs with annotated genes. As shown in Table 2, 7 identified genes that were likely to be shared between AD and obesity. These genes included PSMC3, CELF1, MYBPC3, SPI1, APOE, MTCH2 and RAPSN. The annotated gene for the overlapped SNPs, rs405509 at $\mathrm{p}$-value $\leq 1.0 \mathrm{E}-07$ is APOE.

The functional enrichment analysis of these genes was performed using DAVID for KEGG pathway and GO term enrichment analysis. We obtained significant enrichment of the annotated genes in 10 KEGG pathways. Selected enriched KEGG pathways listed in Table 2 pertained to proteasome, osteoclast differentiation, hypertrophic cardiomyopathy, dilated cardiomyopathy, Epstein-Barr virus and TLV-I infection, and several cancer associated pathways.

\section{DISCUSSION}

The present bioinformatics analysis explored the overlapped genes and biological pathways linking obesity and $\mathrm{AD}$ based on the available meta-GWAS statistics. When setting the threshold at $p$-value $\leq 1.0 \mathrm{E}$ 05, 31 overlapped SNPs were identified to be associated with both AD and obesity. These overlapped SNPs were linked to 7 genes, including PSMC3, CELF1, MYBPC3, 
SPI1, APOE, MTCH2 and RAPSN. Further functional enrichment analysis observed 10 biological pathways, including proteasome, osteoclast differentiation, hypertrophic cardiomyopathy, dilated cardiomyopathy, Epstein-Barr virus and TLV-I infection, as well as several cancer associated pathways.

The results were consistent with current available evidence. APOE gene encodes a protein that transports cholesterol and other types of lipids in the bloodstream. The APOE4 allele is proven to be a strong genetic risk factor for $\mathrm{AD}$ [13-15]. APOE gene is found to play a key role in modulating lipid metabolism and obesity $[16,17]$. Interestingly, a recent study investigated the effect of interaction of APOE $\varepsilon 4$ allele status with BMI on cognitive decline and showed that cognitive decline was differentially associated with BMI and APOE $\varepsilon 4$ allele status [18]. Obesity is characteristic of chronic low-grade inflammation, and inflammation is an important factor in the pathogenesis of AD [19-22]. Proteasome is a multicatalytic complex to functions in the degradation of polyubiquitinated proteins. Many studies support the possible involvement of the proteasome in AD neuropathology [23-25]. The association of polymorphisms of proteasomal genes with obesity has been investigated [26,27]. In addition, increasing evidence support that osteoclast was associated with both obesity and AD [28, 29].

There are some limitations to be noted. It is worth mentioning that there are gender differences for both obesity and AD [30-32], which may arise in part from genetic factors, while the gender subgroup analysis cannot be performed. In addition, the present analysis was based on comprehensive large-scale GIANT and IGAP statistics, while other GWAS studies not included may potentially affect the outcome.

\section{MATERIALS AND METHODS}

The data source and analytical methods were detailed as follows. First, SNPs of obesity were collected from the meta-GWAS statistics of the GIANT data set covering 322,154 participants of European descent and 17,072 participants of non-European descent [33]. SNPs of AD were obtained from the meta-GWAS statistics of the IGAP data set, comprised of 17,008 AD cases and 37,154 controls [34]. Second, through comparing the GIANT and IGAP data, the overlapped SNPs for AD and obesity were identified with multiple $\mathrm{p}$-value as cutoff criteria. Third, using the database of Single-Nucleotide Polymorphism at the National Center for Biotechnology Information, the location and mapped genes of the identified overlapped SNPs for AD and obesity were analyzed. Fourth, to better understand the functions of these genes, we performed R. Kyoto Encyclopedia of Genes and Genomes (KEGG) [35] pathway and gene ontology (GO) [36] enrichment analyses using the web-based search engine Visualization and Integrated Discovery (DAVID) [37] and p-value of 0.05 was set as the threshold of significance.

\section{CONCLUSIONS}

To summarize, by bioinformatics analysis of two meta-GWAS statistic of AD and obesity, we obtained the genetic factors that links obesity to AD. The findings have important implications for future genetic and clinical studies.

\section{ACKNOWLEDGMENTS}

This work was supported by the Shandong Provincial Science Foundation for Distinguished Young Scholars (Grant No. JQ201508).

\section{CONFLICTS OF INTEREST} interest.

The authors declared no potential conflicts of

\section{REFERENCES}

1. Querfurth HW, LaFerla FM. Alzheimer's disease. N Engl J Med. 2010; 28:329-344.

2. Alzheimer's Disease International. World Alzheimer Report 2015, The Global Impact of Dementia. 2015. https://www. alz.co.uk/research/world-report-2015.

3. Haslam DW, James WP. Obesity. Lancet. 2005; 366:11971209.

4. Rimm EB, Stampfer MJ, Giovannucci E, Ascherio A, Spiegelman D, Colditz GA, Willett WC. Body size and fat distribution as predictors of coronary heart disease among middle-aged and older US men. Am J Epidemiol. 1995; 141:1117-1127.

5. Kahn SE, Hull RL, Utzschneider KM. Mechanisms linking obesity to insulin resistance and type 2 diabetes. Nature. 2006; 444:840-846.

6. Guh DP, Zhang W, Bansback N, Amarsi Z, Birmingham $\mathrm{CL}$, Anis AH. The incidence of co-morbidities related to obesity and overweight: a systematic review and metaanalysis. BMC Public Health. 2009; 9:88.

7. Renehan AG, Tyson M, Egger M, Heller RF, Zwahlen M. Body-mass index and incidence of cancer: a systematic review and meta-analysis of prospective observational studies. Lancet. 2008; 371:569-578.

8. Calle EE, Rodriguez C, Walker-Thurmond K, Thun MJ. Overweight, obesity, and mortality from cancer in a prospectively studied cohort of U.S. adults. N Engl J Med. 2003; 348:1625-1638.

9. Letra L, Santana I, Seiça R. Obesity as a risk factor for 
Alzheimer's disease: the role of adipocytokines. Metab Brain Dis. 2014; 29:563-568.

10. Gustafson D, Rothenberg E, Blennow K, Steen B, Skoog I. An 18-year follow-up of overweight and risk of Alzheimer disease. Arch Intern Med. 2003; 163:1524-1528.

11. Whitmer RA, Gunderson EP, Quesenberry CP, Zhou J, Yaffe K. Body mass index in midlife and risk of Alzheimer disease and vascular dementia. Curr Alzheimer Res. 2007; 4:103-109.

12. Emmerzaal TL, Kiliaan AJ, Gustafson DR. 2003-2013: a decade of body mass index, Alzheimer's disease, and dementia. J Alzheimers Dis. 2015; 43:739-755.

13. Altmann A, Tian L, Henderson VW, Greicius MD. Alzheimer's Disease Neuroimaging Initiative Investigators. Sex modifies the APOE-related risk of developing Alzheimer disease. Ann Neurol. 2014; 75:563-573.

14. Corder EH, Saunders AM, Strittmatter WJ, Schmechel DE, Gaskell PC, Small GW, Roses AD, Haines JL, PericakVance MA. Gene dose of apolipoprotein E type 4 allele and the risk of Alzheimer's disease in late onset families. Science. 1993; 261:921-923.

15. Farrer LA, Cupples LA, Haines JL, Hyman B, Kukull WA, Mayeux R, Myers RH, Pericak-Vance MA, Risch $\mathrm{N}$, van Duijn CM. Effects of age, sex, and ethnicity on the association between apolipoprotein E genotype and Alzheimer disease. A meta-analysis. APOE and Alzheimer Disease Meta Analysis Consortium. JAMA. 1997; 278:1349-1356.

16. Kolovou GD, Anagnostopoulou KK, Kostakou P, Giannakopoulou V, Mihas C, Hatzigeorgiou G, Vasiliadis IK, Mikhailidis DP, Cokkinos DV. Apolipoprotein E gene polymorphism and obesity status in middle-aged men with coronary heart disease. In Vivo. 2009; 23:33-39.

17. Srinivasan SR, Ehnholm C, Elkasabany A, Berenson GS. Apolipoprotein E polymorphism modulates the association between obesity and dyslipidemias during young adulthood: The Bogalusa Heart Study. Metabolism. 2001; 50:696-702.

18. Rajan KB, Skarupski KA, Rasmussen HE, Evans DA. Gene-environment interaction of body mass index and apolipoprotein E $\varepsilon 4$ allele on cognitive decline. Alzheimer Dis Assoc Disord. 2014; 28:134-140.

19. Dandona P, Aljada A, Bandyopadhyay A. Inflammation: the link between insulin resistance, obesity and diabetes. Trends Immunol. 2004; 25:4-7.

20. Zeyda M, Stulnig TM. Obesity, inflammation, and insulin resistance--a mini-review. Gerontology. 2009; 55:379-386.

21. Zotova E, Nicoll JA, Kalaria R, Holmes C, Boche D. Inflammation in Alzheimer's disease: relevance to pathogenesis and therapy. Alzheimers Res Ther. 2010; 2:1.

22. Lee YJ, Han SB, Nam SY, Oh KW, Hong JT. Inflammation and Alzheimer's disease. Arch Pharm Res. 2010; 33:15391556.

23. Checler F, Costa CA, Ancolio K, Chevallier N, Lopez-Perez
E, Marambaud P. Role of the proteasome in Alzheimer's disease. Biochim Biophys Acta. 2000; 1502:133-138.

24. Hol EM, van Leeuwen FW, Fischer DF. The proteasome in Alzheimer's disease and Parkinson's disease: lessons from ubiquitin B+1. Trends Mol Med. 2005; 11:488-495.

25. Ross CA, Pickart CM. The ubiquitin-proteasome pathway in Parkinson's disease and other neurodegenerative diseases. Trends Cell Biol. 2004; 14:703-711.

26. Bollinger LM, Powell JJ, Houmard JA, Witczak CA, Brault JJ. Skeletal muscle myotubes in severe obesity exhibit altered ubiquitin-proteasome and autophagic/lysosomal proteolytic flux. Obesity (Silver Spring). 2015; 23:11851193.

27. Kupca S, Sjakste T, Paramonova N, Sugoka O, Rinkuza I, Trapina I, Daugule I, Sipols AJ, Rumba-Rozenfelde I. Association of obesity with proteasomal gene polymorphisms in children. J Obes. 2013; 2013:638154.

28. Halade GV, El Jamali A, Williams PJ, Fajardo RJ, Fernandes G. Obesity-mediated inflammatory microenvironment stimulates osteoclastogenesis and bone loss in mice. Exp Gerontol. 2011; 46:43-52.

29. Cui S, Xiong F, Hong Y, Jung JU, Li XS, Liu JZ, Yan $\mathrm{R}$, Mei L, Feng X, Xiong WC. APPswe/A $\beta$ regulation of osteoclast activation and RAGE expression in an agedependent manner. J Bone Miner Res. 2011; 26:1084-1098.

30. Lovejoy JC, Sainsbury A. Stock Conference 2008 Working Group. Sex differences in obesity and the regulation of energy homeostasis. Obes Rev. 2009; 10:154-167.

31. Kim S, Kim MJ, Kim S, Kang HS, Lim SW, Myung W, Lee Y, Hong CH, Choi SH, Na DL, Seo SW, Ku BD, Kim $\mathrm{SY}$, et al. Gender differences in risk factors for transition from mild cognitive impairment to Alzheimer's disease: A CREDOS study. Compr Psychiatry. 2015; 62:114-122

32. Mielke MM, Vemuri P, Rocca WA. Clinical epidemiology of Alzheimer's disease: assessing sex and gender differences. Clin Epidemiol. 2014; 6:37-48.

33. Locke AE, Kahali B, Berndt SI, Justice AE, Pers TH, Day FR, Powell C, Vedantam S, Buchkovich ML, Yang J, Croteau-Chonka DC, Esko T, Fall T, et al. Genetic studies of body mass index yield new insights for obesity biology. Nature. 2015; 518:197-206.

34. Lambert JC, Ibrahim-Verbaas CA, Harold D, Naj AC, Sims R, Bellenguez C, DeStafano AL, Bis JC, Beecham GW, Grenier-Boley B, Russo G, Thorton-Wells TA, Jones N, et al. Meta-analysis of 74,046 individuals identifies 11 new susceptibility loci for Alzheimer's disease. Nat Genetics. 2013; 45:1452-1458.

35. Kanehisa M, Goto S. KEGG: kyoto encyclopedia of genes and genomes. Nucleic Acids Res. 2000; 28:27-30.

36. Ashburner M, Ball CA, Blake JA, Botstein D, Butler H, Cherry JM, Davis AP, Dolinski K, Dwight SS, Eppig JT, Harris MA, Hill DP, Issel-Tarver L, et al. Gene ontology: tool for the unification of biology. Nat Genet. 2000; 25:2529. 
37. Huang DW, Sherman BT, Lempicki RA. Systematic and integrative analysis of large gene lists using DAVID bioinformatics resources. Nat Protoc. 2009; 4:44-57. 